\title{
CZU:633.854.78:631.527.5
}

https://doi.org/10.53040/gppb7.2021.63

\section{ANALIZA DIFERITOR HIBRIZI DE PERSPECTIVĂ ÎN SECTOARELE COMPARATIVE}

\author{
Martea Rodica ${ }^{1}$, Gâscă Ion ${ }^{1,2}$, Cucereavîi Aliona ${ }^{1,2}$ \\ ${ }^{1}$ Centrul de Cercetări Științifice Genetică Funcțională, Institutul de Cercetare și Inovare, Universitatea \\ de Stat din Moldova, Chișinău, Republica Moldova, \\ ${ }^{2}$ AMG - Agroselect Comert SRL, Soroca, Republica Moldova \\ e-mail: rodica.martea@gmail.com
}

\begin{abstract}
Sunflower (Helianthus annuus L.) holds a prominent place in global agriculture as one of the most important crops from economical and alimentary aspect and is highly demanded both on domestic and international markets.

Current study focuses on the analysis of morphological and productivity characteristics for a number of sunflower hybrids obtained in AMG-Agroselect Comerts SRL breeding programs. The values for the main biometric parameters were analyzed.

Evaluation of the productivity indices demonstrates lower values in 2020 for most parameters of productivity compared to 2019, specific climatic conditions of the mentioned year explain this fact.

'Nistru' hybrid in 2019 showed the best performance in four cases (leaf number, capitulum diameter, seed weight per capitulum and TKW). 'Zimbru' hybrid showed minimal values in five cases (plant height, capitulum diameter, seed weight per capitulum, seed number per capitulum and TKW).

Key words: capitulum diameter, Helianthus annuus L., plant height, thousand kernel weight, seed hectoliter weight, whole seed weight per capitulum, leaf number per plant, whole seed number per capitulum, productivity.
\end{abstract}

\section{Introducere}

H. annuus L. este practic unica cultură oleaginoasă din Republica Moldova, țara noastră situânduse, conform datelor FAO, pe locul 8 în topul celor mai mari producători de semințe de floarea-soarelui (29 țări producătoare) [8].

Datorită cantității și calității uleiul utilizat pe larg în nutriția umană, astăzi floarea-soarelui este a patra cultură oleaginoasă în lume după soia, palmier și rapiță [6], producția globală de floarea-soarelui în anul 2020 fiind estimată la 54,96 milioane de tone [8].

În comparație cu alte culturi oleaginoase, floarea-soarelui asigură un randament maxim de ulei la o unitate de suprafață, cu un spectru larg de utilizare, prezentând astfel un impact economic major [2]. Sporirea considerabilă a producției de semințe şi ulei, determinată de extinderea pe scară largă a hibrizilor de floarea-soarelui cu productivitate înaltă, situează cultura pe poziții avantajoase nu numai în competiția cu celelalte plante oleaginoase, dar şi cu alte culturi preferențiale din agricultura mondială.

Se constată că țara noastră are o tradiție îndelungată în cultivarea acestei culturi, datorită avantajelor sale economice, agroalimentare, industriale şi curative, plasându-se pe locul al treilea după porumbul pentru boabe și grâu [1].

Principalul obiectiv strategic în procesul de ameliorarea florii-soarelui constituie crearea hibrizilor cu potențial sporit de productivitate. În ultimii ani tehnologia de cultivare a florii-soarelui a devenit mai performantă, iar calitatea hibrizilor a crescut și s-a îmbunătăţit constant [5].

Creșterea şi dezvoltarea culturilor agricole, inclusiv a florii-soarelui, în mare măsură depinde de influența factorilor de mediu. Astfel, realizarea programului genetic în ontogeneză și, respectiv, recolta acesteia este un rezultat al raportului genotip-tehnologii-mediu, capacitatea de producție fiind o însușire ereditară, puternic influențată de condițiile de mediu [7]. Tehnologia de cultivare a florii-soarelui este complexă și flexibilă, modificându-se în dependență de condițiile climatice și economice din an în an atât, pentru întreaga perioadă de vegetație pentru întreaga regiune, cât și pentru un câmp aparte.

În cadrul programelor de ameliorare a florii-soarelui, elementele de productivitate sunt reprezentate de parametri precum: diametrul calatidiului, numărul de semințe pline pe capitul şi greutatea acestora, 
masa a 1000 boabe și masa hectolitrică a semințelor. Aceste caractere corelează cu înălțimea plantelor și numărul de frunze per plantă. În acest context, studiile prezentate au fost focusate pe analiza principalilor indici morfologice și de producție la hibrizii de floarea-soarelui din sectoarele comparative, și corelarea cu productivitatea acestora, pe parcursul anilor 2019 și 2020.

\section{Materiale şi metode}

Materialul biologic. Investigațiile au fost realizate pe parcursul anilor 2019-2020, cu utilizarea unui set de 25 de hibrizi de floarea-soarelui, creați în cadrul lucrărilor ameliorative în AMG-Agroselect Comerţ SRL:

\begin{tabular}{|c|c|c|c|}
\hline Codru & Oscar & 454 & 1719 \\
\hline Dacia & US 235 CLP & 457 & 1721 \\
\hline Talmaz & US 237 SU & 618 & 1722 \\
\hline Zimbru & US 2472 CLP & 1583 & 1727 \\
\hline Cezar & US 2137 SU & 1625 & \\
\hline Nistru & 413 & 1686 & \\
\hline Doina & 415 & 1718 & \\
\hline
\end{tabular}

Opt dintre hibrizii cercetați sunt omologați (Codru, Dacia, Talmaz, Zimbru, Doina, Nistru, Cezar și Oscar), patru hibrizi sunt transmiși la Comisia de Stat pentru Testarea Soiurilor de Plante (US 235 CLP, US 237 SU, US 2472 CLP și US 2137 SU), iar 13 hibrizi sunt testați în culturile comparative pe câmpul experimental (413, 415, 454, 457, 618, 1583, 1625, 1686, 1718, 1719,1721, 1722 și 1727).

Condiții de cultivare. Semănatul s-a efectuat pe 21 aprilie (2019) și 24 aprilie (2020), premergătorul fiind cereale păioase pe un sol, care a fost prelucrat conform tehnologiilor recomandate [9], urmată de fertilizarea solului ( $70 \mathrm{~kg} / \mathrm{ha}$ de $\mathrm{N}_{16} \mathrm{P}_{16} \mathrm{~K}_{16}$ ), introducerea erbicidului (Avangard Duo $\mathrm{SC}-3,0$ 1/ha) și a insecticidului (Force 1,5G - 12,0 kg/ha).

Semnatul în cultura comparativă s-a efectuat manual, în patru repetiții, pe parcele cu suprafața de $33.6 \mathrm{~m}^{2}$, cate 2-3 semințe în cuib și 4-5 cuiburi la metru liniar. În faza de 2-3 perechi de frunze adevărate s-a realizat răritul plantulelor. Pentru menținerea câmpului curat de buruieni și dezvoltarea optimă a plantelor s-au efectuat doua prașe manuale și o prelucrare mecanizată între rânduri.

Colectarea datelor biologice. S-au efectuat un șir de măsurări biometrice: înălțimea plantei, numărul de frunze, diametrul calatidiului, masa semințelor a unui calatidiu și numărul de semințe pe calatidiu.

Înălțimea medie a plantelor de floarea-soarelui s-a determinat în câmp, prin măsurarea tulpinii, de la nivelul solului până sub calatidiu, la 10 plante pentru fiecare lot studiat şi repetiţie. Numărul mediu de frunze pe plantă s-a determinat prin numărarea frunzelor de la 10 plante din fiecare repetiție. Determinarea valorilor mărimii calatidiului s-a realizat prin măsurarea acestora la câte 10 plante luate în studiu, pentru fiecare genotip şi repetiție, cu ajutorul unei rigle gradate. Numărul mediu de semințe pe calatidiu s-a apreciat prin numărarea tuturor semințelor pline din calatidiile a 10 plante, pentru fiecare număr luat în studiu şi fiecare repetiţie. Determinarea greutății semințelor a unui calatidiu a rezultat prin cântărirea acestora la balanța analitică CBA-300.

Elementele de productivitate la floarea-soarelui estimate au fost recolta, masa a 1000 boabe și masa hectolitrică a semințelor. Masa a 1000 de boabe (MMB) s-a determinat în laborator, prin numărarea a două probe de câte 500 semințe și cântărirea acestora la balanța analitică CBA-300, calculul mediei între probe şi înmulţirea la doi, pentru fiecare genotip şi repetiţie. Masa hectolitrica (MHL) s-a determinat prin cântărirea a 2 probe a câte un volum de un litru de semințe cu ajutorul balanței, calculul mediei probelor pentru 10 plante din fiecare număr luat în studiu şi fiecare repetiţie

Prelucrarea statistică a datelor. Datele primare obținute în cadrul cercetărilor au fost supuse prelucrării statistice (media valorilor înregistrate) în programul computerizat Excel. 


\section{Rezultate şi discuţii}

Evaluarea principalilor indicatori agronomici s-a realizat pentru 25 de hibrizi de floarea-soarelui, în perioada anilor 2019-2020, pe câmpurile experimentale din orașul Soroca, în trei repetiții biologice.

În urma observațiilor efectuate se constată că înălțimea medie a plantelor a variat de la $150,0 \mathrm{~cm}$ (US 235 CLP și 1868) până la 186,0 cm (Doina) în anul 2019, și respectiv, de la 132,0 cm (Zimbru) până la $163,0 \mathrm{~cm}$ (415) în anul 2020. Plantele studiate au prezentat o talie medie mai mare în anul 2019 (168,3 $\mathrm{cm})$, comparativ cu rezultatele înregistrate în anul $2020(150,1 \mathrm{~cm})$ (Figura 1).

Un număr mare de frunze pe tulpină cu internoduri scurte indică productivitatea mare a acestor genotipuri [1]. Analizând numărul de frunze per plantă constatăm, că media pentru acest caracter în primul an a constituit 29 frunze pe plantă, iar în al doilea an - 28 frunze pe plantă. (Figura 1). La nivelul hibrizilor, hibridul Nistru prezintă numărul maxim de frunze pe tulpină, atât în anul 2019 (34), cât și în anul 2020 (36). Totodată, cele mai puține frunze în anul 2019 au fost relevate de doi hibrizii: Zimbru și 1727 (27), iar în anul 2020 de trei hibrizi: Dacia, Oscar și 1727 (26).

Diametrul calatidiului este o trăsătură mai puțin influențată de factorii genetici şi mai mult de către condițiile de mediu și perioada de vegetație [2]. În cadrul cercetărilor realizate media diametrul calatidiului pentru cei doi ani a fost apropiată, $21,68 \mathrm{~cm}$ în primul an, și respectiv, 21,24 cm în următorul an (Figura 1), dacă în anul 2019 valorile au fost de la $20 \mathrm{~cm}$ (1727) până la 24 cm (Nistru), iar în anul 2020 diametrul a fost de la $19 \mathrm{~cm}$ (Zimbru) până la $24 \mathrm{~cm}$ (Doina).

Alt indice important în ameliorare la floarea-soarelui îl constituie masa semințelor unui calatidiu [1]. Masa lor indică faptul, că astfel de semințe au rezerve de nutriţie suficiente și embrion bine dezvoltat, astfel semințele care posedă masă mare sunt binevenite în producerea de semințe. Rezultatele privind masa semințelor unui calatidiu arată diferențe semnificative pe parcursul celor doi studiaţi. Media în anul 2019 a fost de 111,9 g, iar 2020 - 73,5 g (Figura 1), aceasta fiind explicată prin condițiile climaterice specifice ale acestui an. La nivelul hibrizilor cercetați, cea mai mare valoare medie din cadrul a experimentului (147,8 g) a fost atestată de hibridul Nistru în anul 2019, iar cea mai mică valoare a experimentului (46,3 g) se atestă în cazul hibridului Zimbru în anul 2020. Un fapt curios se remarcă în cazul hibridului 1625, acesta în primul an a înregistrat valoarea minimă a anului $(81,4 \mathrm{~g})$, tot el în al doilea an a prezentat cea mai mare masă dintre toți hibrizii de $103 \mathrm{~g}$.

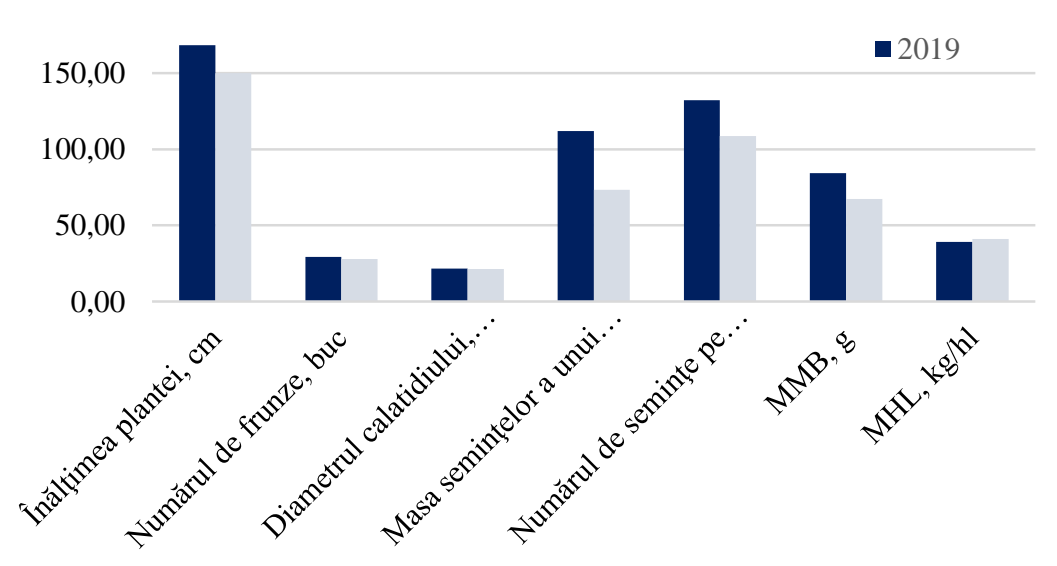

Figura 1. Indicatorii agronomici a hibrizilor de floarea-soarelui

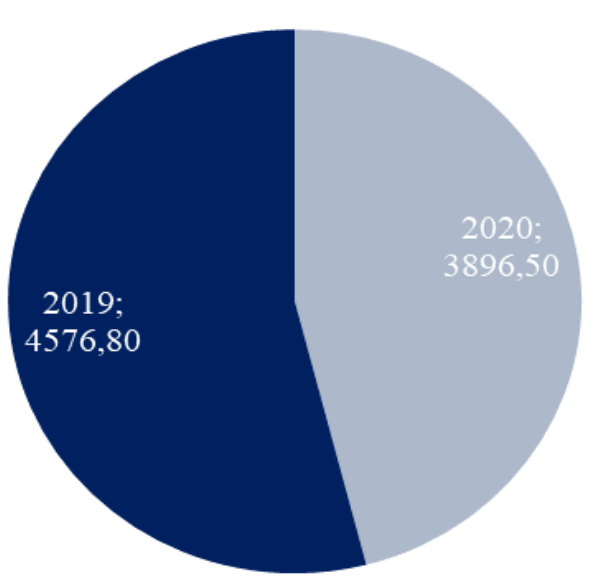

Fig. 2. Recolta medie, $\mathrm{kg} / \mathrm{ha}$

Un indicator important al potențialului de producție îl constituie și numărul de semințe pline [1]. Valorile înregistrate pentru această însușire au variat de la 955 până la 1607 (2019), și respectiv, de la 805 până la 1450 (2020). Numărul mediu a fost și el mai mare în anul 2019 de 1322,1, comparativ cu 1087,8 semințe în anul 2020 (Figura 1). Hibridului 1625 la fel ca și în cazul masei semințelor unui calatidiu are în primul an a prezentat valoarea minimă a anului (955), tot el în al doilea an a prezentat numărul cel mai mare dintre toți hibrizii de 1450. Dintre hibrizii cercetați, cel mai mic număr din întreg experimentul (805), înregistrată în anul 2020, a fost atestată de hibridul Zimbru, la fel ca și în cazul masei semințelor unui calatidiu. 
Masa a 1000 de boabe este o însuşire variabilă, influențată de factori genetici şi de mediu. Valoarea acestui caracter variază atât între diferite genotipuri în aceeași locaţie, cât și într-un singur genotip în locații diferite [4]. În cazul de față, analiza valorilor privind masa a 1000 de boabe, în anul 2019 evidenţiază valori medii de 84,2 g, care au fost net superioare față de valoarea medie înregistrată în anul 2020 - 67,4 g (Figura 1), fapt condiţionat de condițiile climaterice specifice din 2020. La nivelul hibrizilor, în primul an, valorile au variat de la 70,4 g (454), până la 98,3 g (Nistru) și în al doilea an de la 57,5 g (Zimbru), până la 80,7 g (Talmaz).

Masa hectolitrică a hibrizilor de floarea-soarelui, este singurul indicator dintre cei analizați care a arătat o medie mai mare în anul 2020 (41), comparativ cu datele din 2019 (39,2). Cea mai mare MHL se constată pentru hibridul $1722(41,75 \mathrm{~kg} / \mathrm{hl})$ în anul 2019, și respectiv, hibridul $1718(44,25 \mathrm{~kg} / \mathrm{hl})$ în anul 2020. Se evidenţiază hibridul Talmaz cu valori minime, atât în anul $2019(35,3 \mathrm{~kg} / \mathrm{hl})$,

cât și în anul $2020(36,05 \mathrm{~kg} / \mathrm{hl})$.

Analizând productivitatea se constată că recolta hibrizilor de

floarea-soarelui a variat destul de mult pe parcursul celor doi ani analizaţi. Astfel, în anul 2019 recolta media a fost de 4576,9 kg/ha, iar în anul 2020 valorile înregistrate au fost mai mici, respectiv de la 3896,5 $\mathrm{kg} / \mathrm{ha}$ (Figura 2), ceea ce poate fi explicat prin condițiile climaterice specifice ale anului respectiv. În conformitate cu datele privind recolta la nivelul hibrizilor, cea mai mare valoare a fost înregistrată în cazul hibridului 415 - 5224,3 kg/ha (2019), și respectiv hibridul 457 - 4818,5 kg/ha (2020). Cea mai mică recoltă se atestat de hibridul Doina - 4090,1 kg/ha (2019), și respectiv, hibridul Talmaz - 2904,8 kg/ha (2020) (Figura 3).

În condiţiile de cultivare a celor 25 de hibrizi de floarea-soarelui, parametrii biometrici şi cei de productivitate au relevat valori specifice în funcţie de hybrid (Figura 3). Hibrizii au prezentat valori mai ridicate a recoltei în anul 2019 rezultate corelate și cu datele obținute pentru indicii biometrici analizați mai sus.

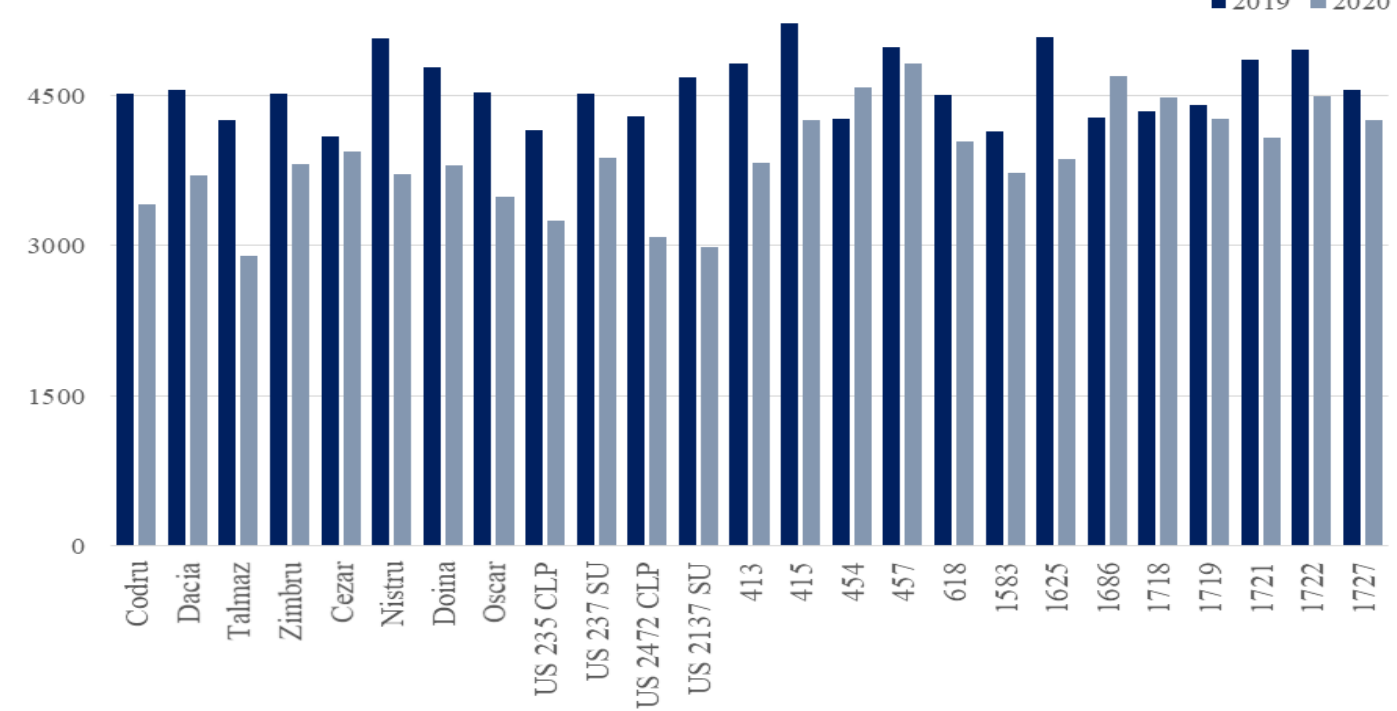

Figura 3. Recolta medie a hibrizilor cercetați, $\mathrm{kg} / \mathrm{ha}$

Generalizând rezultatele, se atestă faptul că în anul 2020 că parametrii biometrici şi indicatorii de productivitate au prezentat valori mai mici, comparativ cu datele din anul 2019, ceea ce poate fi corelat atât de cantitățile reduse de precipitații în perioada iunie-iulie 2020, perioadă care corespunde celor mai critice perioade de dezvoltare a florii-soarelui (formarea calatidiului şi înflorirea calatidiului), cât și de deficitul de apă din sol specific perioadei premergătoare a anului agricol concret, care corespunde perioadei 1 octombrie 2019 - 1 aprilie 2020, adică perioada de până la semănat.

Dintre hibrizii analizaţi, hibridul Nistru în anul 2019 a prezentat cele mai bune rezultate în patru cazuri (numărul de frunze, diametrul calatidiului, masa semințelor a unui calatidiu și MMB), tot acest hibrid prezintă rezultate maxime pentru indicatorul numărul de frunze și în anul 2020.

În același timp, hibridul Zimbru în anul 2020 a arătat valori minime în cinci cazuri (înălțimea plantei, diametrul calatidiului, masa semințelor a unui calatidiu, numărul de semințe pe calatidiu, și $M M B$ ), tot acest hibrid prezintă rezultate minime pentru indicatorul numărul de frunze și în anul 2020. 


\section{Concluzii}

Rezultatele studiului efectuat au pus în evidență deosebiri semnificative pe parcursul celor doi ani analizați. Pe parcursul anului 2020, toți parametrii de productivitate şi indicatorii biometrici (cu excepția masei hectolitrice) au arătat valori mai scăzute, comparativ cu anul 2019, acestea fiind corelate atât de cantităţile reduse de precipitații în perioada iunie-iulie, perioadă critică pentru dezvoltarea florii-soarelui, cât şi de deficitul de apă din sol specific pentru lunile septembrie-aprilie.

Datele privind productivitatea celor 25 hibrizi de floarea-soarelui incluși în studiu, au arătat o variație semnificativă, astfel, în anul 2019 recolta media a fost de 4576,9 kg/ha, iar în anul 2020 valorile înregistrate au fost mai mici, de numai $3896,5 \mathrm{~kg} / \mathrm{ha}$.

1. Hibridul Nistru în anul 2019 a prezentat cele mai bune rezultate în patru cazuri (numărul de frunze, diametrul calatidiului, masa semințelor a unui calatidiu și MMB).

2. Hibridul Zimbru în anul 2020 a arătat valori minime în cinci cazuri (înălțimea plantei, diametrul calatidiului, masa semințelor a unui calatidiu, numărul de semințe pe calatidiu, și MMB).

Lucrarea dată a fost efectuată în cadrul proiectului 20.80009.5107.01 Studii genetico-moleculare și biotehnologice ale florii-soarelui în contextul asigurării managementului durabil al ecosistemelor agricole, (Program de Stat 2020-2023).

\section{Bibliografie}

1. CUCEREAVÎI A. Caracterele agrobiologice importante la germoplasma de floarea-soarelui pentru crearea hibrizilor performanți. Teză de doctor în științe agricole, 2018, - 30 p.

2. JOCKOVIĆ, M., et al. Evaluation of sunflower hybrids in multi-environmental trial (MET) In: Turk. J. Field Crops. 2019, 24:202:210. doi:10.17557/tjfc.645276

3. MARINKOVIĆ R., DOZET B., VASIĆ D. Oplemenjivaje suncokreta. Novi Sad: Scolska knjiga. 2003, - 368 p.

4. MARINKOVIĆ R., MARJANOVIĆ-JEROMELA A. Assessment of components of genetic variance of mass 1000 seeds in sunflower (Helianthus annuus L.). In: Genetika, 2005, nr 37(2):145-153.

5. PILORGÉ, E. Sunflower in the global vegetable oil system: situation, specificities and perspectives. In: $O C L$. 2020, 27, 34:1-11. doi.org/10.1051/ocl/20200

6. RAUF S., JAMIL N., ALI TARIQ S., KHAN M., KAUSAR M. Progress in modification of sunflower oil to expand its industrial value. In: J. Sci. Food Agric. 2017, 97:1997-2006.

7. STEFAN V., et al. Floarea soarelui. Buzău: ALPHA MDN. 2008, p. 104-129

8. Sunflower Production by Country, http://www.worldagriculturalproduction.com/crops/ sunflower.aspx

9. VRONSCHIH M., BOINCEAN B., BUCIUCEANU M. Floarea-soarelui: (îndrumar), Chișinău, 2002, - 48 p. 